\title{
BEHAVIORAL INTERACTIONS BETWEEN PARASITES AND HOSTS: HOST SUICIDE AND THE EVOLUTION OF COMPLEX LIFE CYCLES
}

\author{
Deborah R. Smith Trail* \\ Department of Zoology, University of California, Davis, California 95616 \\ Submitted January 18, 1978; Accepted February 14, 1979
}

The study of parasites and their hosts has typically focused on the physiological, morphological, and immunological adaptations to parasitism, adaptations which the parasite employs to survive and reproduce in the host and those used by the host in self-defense. This paper explores instead some of the behavioral aspects of the parasite-host relationship. The parasite can alter the behavior of the host in ways which will facilitate dispersal of parasite propagules to new hosts or increase the amount of energy available for the parasite's growth. The host in turn can employ behavioral defense mechanisms as well as the more familiar physiological and immunological defense mechanisms. In one of the most interesting forms of behavioral defense, a host may use its own death to increase its inclusive fitness. Since some types of parasitic infections cause death or sterility of the host they also result in the host's genetic death. Although the host may be unable to affect its individual reproductive fitness it can affect its inclusive fitness. The host can change the time and nature of its death; it can "commit suicide," or behave aberrantly and increase the probability of death by predation, thus preventing the maturation of its parasite and lowering the risk of parasitic infection for other members of the host species. If the mature parasite would have been more likely to infect the host's kin than nonkin, the host's suicidal behavior will increase its inclusive fitness and thus have a positive selective value.

I will first discuss four types of parasitic life cycles and behavioral interactions between these parasites and their hosts. The phenomenon of host suicide and situations where this phenomenon might be expected to occur will be discussed in detail. Finally, I will outline the role that host suicide may have played in the evolution of complex life cycles.

\section{DEFINITIONS}

To understand the situations in which various types of behavioral manipulation of hosts by their parasites or behavioral defense by hosts against their parasites can be employed, it is necessary to first outline the characteristics of the four types of endoparasites which will be discussed (table 1). Since ectoparasites (or

* Present address: Division of Biological Sciences, Section of Neurobiology and Behavior, Cornell University, Ithaca, New York 14853.

Am. Nat. 1980. Vol. 116, pp. 77-91.

(c) 1980 by The University of Chicago. 0003-0147/80/1601-0004\$01.44 
TABLE 1

Characteristics of Four Major Types of Endoparasites*

\begin{tabular}{|c|c|c|c|c|c|c|}
\hline & $\begin{array}{l}\text { Free- } \\
\text { Living } \\
\text { Stage }\end{array}$ & $\begin{array}{c}\text { No. of } \\
\text { Parasite } \\
\text { Individuals } \\
\text { per Host }\end{array}$ & $\begin{array}{l}\text { No. of } \\
\text { Hosts } \\
\text { Occupied } \\
\text { by One } \\
\text { Parasite }\end{array}$ & $\begin{array}{c}\text { Size of } \\
\text { Parasite }\end{array}$ & $\begin{array}{c}\text { Effect of } \\
\text { Single } \\
\text { Parasite } \\
\text { on Host's } \\
\text { Reproductive } \\
\text { Success }\end{array}$ & $\begin{array}{l}\text { Effect of } \\
\text { Multiple } \\
\text { Infection } \\
\text { on Host's } \\
\text { Reproductive } \\
\text { Success }\end{array}$ \\
\hline $\begin{array}{l}\text { Group } 1 \ldots \\
\quad \text { Parasitoid }\end{array}$ & Present & $\begin{array}{l}1 \text { individual } \\
\text { clone, or } \\
\text { group of } \\
\text { siblings }\end{array}$ & 1 & $\begin{array}{l}\text { Large } \\
1 \%-10 \% \\
\text { host's } \\
\text { body size }\end{array}$ & $\begin{array}{l}\text { Reduce to } \\
\text { zero }\end{array}$ & $\begin{array}{l}\text { Same as single } \\
\text { infection, } \\
\text { reduce to } \\
\text { zero }\end{array}$ \\
\hline $\begin{array}{l}\text { Group } 2 \ldots \\
\text { Castrator }\end{array}$ & $\begin{array}{l}\text { May or may } \\
\text { not be } \\
\text { present }\end{array}$ & $\begin{array}{l}1 \text { individual, } \\
\text { clone, or } \\
\text { group of } \\
\text { siblings }\end{array}$ & 1 & $\begin{array}{l}\text { Large } \\
1 \%-10 \% \\
\text { host's } \\
\text { body size }\end{array}$ & $\begin{array}{l}\text { Reduce, } \\
\text { usually to } \\
\text { zero }\end{array}$ & $\begin{array}{l}\text { Same as single } \\
\text { infection }\end{array}$ \\
\hline $\begin{array}{l}\text { Group } 3 \ldots \\
\text { Single-host } \\
\text { true } \\
\text { parasite }\end{array}$ & $\begin{array}{l}\text { May or may } \\
\text { not be } \\
\text { present }\end{array}$ & 1-many & 1 & $\begin{array}{l}\text { Small } \\
\text { several orders } \\
\text { of magnitude } \\
\text { smaller than host }\end{array}$ & Little effect & $\begin{array}{l}\text { Reduce, amount } \\
\text { variable }\end{array}$ \\
\hline $\begin{array}{l}\text { Group } 4 \ldots \\
\text { Multi-host } \\
\text { true } \\
\text { parasite }\end{array}$ & $\begin{array}{l}\text { May or may } \\
\text { not be } \\
\text { present }\end{array}$ & $\begin{array}{l}\text { 1-many } \\
\text { in definitive } \\
\text { host; no. in } \\
\text { intermediate } \\
\text { varies }\end{array}$ & $2-4$ & $\begin{array}{l}\text { Small } \\
\text { compared to } \\
\text { definitive; } \\
\text { size in } \\
\text { intermediate } \\
\text { varies }\end{array}$ & $\begin{array}{l}\text { Little effect } \\
\text { on definitive; } \\
\text { amount variable: } \\
\text { intermediate } \\
\text { varies }\end{array}$ & $\begin{array}{c}\text { Reduce definitive } \\
\text { host's success, } \\
\text { effect on } \\
\text { intermediate } \\
\text { highly variable }\end{array}$ \\
\hline
\end{tabular}

* After Kuris (1974) 
micropredators) are often able to exploit several individuals of one host species in succession, and since their feeding behavior resembles that of predators, they lie outside the scope of this paper.

Both parasitoids (group 1) and castrators (group 2) undergo growth and development within a single host, typically have a free-living stage, and are large, generally $1 \%-10 \%$ of the host's body weight. They differ in one important respect: A parasitoid causes the death of its host, while a castrator causes permanent or temporary reduction in the host's fertility (Kuris 1974).

True parasites with one host (group 3) and with two or more hosts (group 4) are small, generally several orders of magnitude smaller than the host. A free-living stage may or may not be present. A single parasite generally has little effect on the reproductive success of the host; infection with many parasites of one species or infection with more than one species can have more serious effects on the host. Group 3 and group 4 parasites differ in that group 3 parasites occupy only a single host in their lifetime and are thus said to have a simple life cycle. Group 4 parasites occupy a definitive host, in which parasite reproduction and some growth occur, and one to three intermediate hosts, in which a variable amount of growth, development, and in some groups asexual reproduction occur. Such life cycles are known as complex life cycles.

\section{HOST-PARASITE INTERACTIONS}

The problems faced by parasites. - All parasites face three problems. The first is dispersal of propagules to new hosts. Parasitic groups with free-living stages can accomplish this relatively easily; examples are the parasitoids, in which the free-living stage typically locates and infects new hosts. Parasitic species with no free-living stages must use other methods. The morphological and reproductive adaptations used to accomplish this are well documented in the parasitological literature (Cheng 1973). Less well known are the parasite induced changes in host behavior which facilitate the dispersal of propagules to new hosts. Dence (1958) and Orr (1966) discuss the behavioral effects of the cestode Ligula intestinalis on intermediate fish hosts, and Lester (1971) reports behavioral changes in fish infected with Schistocephalus trematodes. The bivalve mollusc Macoma balthica is an intermediate host for the trematode Parvatrema affinis (Swennen and Ching 1974). These clams feed while buried in the sublittoral and tidal flat mud. Uninfected clams do not leave any conspicuous marks in the sand indicating their presence. Infected clams are concentrated in the higher parts of the tidal flats, closer to the shore, and leave conspicuous zig-zag tracks in the sand (Swennen 1969). The definite hosts are oyster catchers and other shorebirds, which have been observed to use visual as well as tactile cues to find the clams (Hulscher 1973).

The second problem faced by parasites is obtaining sufficient energy for growth, maintenance, and reproduction at the expense of the host. The parasite can alter the host's energy budget to increase the amount of the host's energy potentially available to the parasite. For the purposes of discussion the host's energy can be compartmentalized into a number of more or less discrete units: energy used in the 
maintenance of the host's own tissues and metabolism, energy associated with food getting and digestion, energy used in defense against predators, and the host's energetic investment in reproduction. A certain minimal amount of energy must be allotted to the first three categories simply to keep the host (and its parasite) alive. (The amount of energy may indeed be at this minimum; Negus [1968] notes that many of the biochemical effects seen in molluscs infected with trematodes are similar to those found in starving molluscs.) In addition, if the parasite can reduce the amount of energy the hosts invest in reproductive activities, the amount of energy potentially available to the parasite may be increased. That parasites can induce physiological and morphological changes in their hosts leading to reduced host reproductive output is well documented. (See Baudoin [1975] and Kuris [1974] for reviews; Hartnoll [1962] and Reinhard [1956] for the effects of rhizocephalids on crustaceans; Pan [1965], Uzmann [1953], and Wright [1966] for the effects of trematodes on molluscs.) Behavior patterns also require energy, and parasites are able to induce energy conserving changes in host behavior; hosts can be induced to spend less energy on courtship, reproductive, and aggressive behaviors. One case, the behavior of female hymenopterans infected with strepsipterans (Insecta: Strepsiptera), is discussed below.

Finally, the host must survive until the parasite has matured and is able to reproduce. On the physiological side, parasites will show selective tissue destruction, avoiding ingestion of the host's vital organs too soon. On the behavioral side, parasites should try to reduce the frequency of behaviors on the part of the host which entail exposure to predation or increased risk of accidental death.

Problems faced by infected hosts. - A host infected with a parasite will show a reduction in individual fitness ranging from complete loss of reproductive success to a very small decrease in reproductive success. Threatened with parasitic attack, the host-or potential host-can attempt to increase its reproductive fitness in two ways, which are not mutually exclusive. It can protect itself or it can protect its kin.

Certain actions on the part of the host can prevent infection by a parasite or kill the parasite once it has entered the host's body. Physiological and morphological mechanisms such as the host's immunological system, phagocytic cells, and encapsulation of parasites are well documented (Salt 1963; Cheng 1968, 1973). Behavior patterns can also serve to prevent entry of parasites. Larvae and pupae of insects may struggle violently when attacked by parasitoids; this is especially effective if the parasitoid is smaller than its host. Caterpillars wriggle when attacked, and aphids kick. Askew noted that when the parasitoid wasp Apechthis contacted the pupa of the butterfly Nymphalis urticae the abdomen of the pupa wriggled so violently that "the ichneumonid was often thrown into the air as soon as it lighted" (Askew 1971).

A second defense strategy is to prevent parasitic infection in one's kin. This strategy is discussed in detail below.

Parasitoid-host interactions.-Parasitoids (group 1 parasites) in general do not depend upon their hosts for dispersal. In nearly all cases there is a free-living stage which accomplishes this. For example, the adult females of the majority of parasitic hymenopteran species actively locate and oviposit in the host (Askew 1971). 
Most of the behavioral and physiological modification of the host by parasitoids will involve induced changes in the host's energy budget and mechanisms to prevent accidental death of the host. (One approach would be to repress behavior associated with reproduction. This, of course, puts the parasitoid into the castrator category, which is discussed below.)

The parasitoid may decrease the amount of energy expended in producing or maintaining adult structures and behaviors if they are energetically more expensive than retention of juvenile characters. For example, the braconid wasp Aphidius (Hymenoptera: Braconidae) can cause an aphid nymph to develop into an apterous nondispersive adult instead of the winged form of the adult which disperses over relatively great distances (Askew 1971).

Food-getting behaviors and maintenance of the host's own tissues should not be curtailed until after the host has built up sufficient reserves to supply the parasitoid with the energy needed for its maturation. Wasps of the family Chrysididae lay their eggs on the larvae of Vespidae and Shpecidae (Hymenoptera). The chrysidad larvae will delay feeding on the host larvae until the host larvae themselves have begun feeding and reached a certain size (Askew 1971). Slansky (1978) has shown that larvae of Pieris rapae (Lepidoptera: Pieridae) parasitized by Apanteles glomeratus (Hymenoptera: Braconidae) convert more assimilated energy into biomass and consume energy and nitrogen at higher rates than nonparasitized larvae, while showing a lower metabolic rate. The parasitoid larvae can consume $50 \%-60 \%$ of the energy and $60 \%-70 \%$ of the nitrogen assimilated by their hosts without affecting the hosts' laboratory survival rates.

Last, any behavior on the part of the host which entails exposure to predation or accidental death should be prevented lest the host be killed before the parasitoid has a chance to mature. There are several cases in which the parasitoid causes the insect host to pupate prematurely (Fisher and Sanbourn 1964). In some of these cases this may be a mechanism to keep the host inactive and inconspicuous to predators after it has built up food reserves sufficient to maintain the parasitoid.

A unique type of defense against parasitoids, which combines self-defense and defense of kin, is presented by the leaf-cutting ants, Atta cephalotes. A parasitoid fly, believed to be a member of the genus Apocephalus (Diptera: Phoridae), attacks media workers of the leaf-cutter, laying an egg on the ant's neck; the fly larva burrows into the ant's head and consumes the brain. Unencumbered workers can defend themselves by lunging at the fly with their mandibles, but a media worker carrying a leaf fragment cannot. Instead, these ants allow a tiny worker of the minima caste to ride on the leaf fragment. This ant confronts the attacking fly with its mandibles (Eibl-Eibesfeldt and Eibl-Eibesfeldt 1967).

The host almost invariably dies as a result of a parasitoid infection: its individual fitness is reduced to zero. The host's inclusive fitness, however, includes both its individual fitness and the sum of the fitnesses of each of its relatives, appropriately weighted for the fraction of the genome shared by common descent. (For a more thorough discussion see Hamilton 1964, 1972; West Eberhard 1975.)

Kin selection theory suggests that an infected host can increase its inclusive fitness by lowering the risk of parasitic infection in its kin. In those cases where the mature parasitoid emerging from the host is more likely to infect the host's kin than nonkin the host can increase its inclusive fitness by preventing maturation of 
the parasitoid. An infected individual may behave in such a manner as to become more conspicuous to predators or easier to capture. As a result the host may be killed before the parasitoid is able to mature. The host's kin are now protected against infection by this particular parasitoid individual. Natural selection can act to reinforce this "suicidal" behavior. Even a very small increase in inclusive fitness will be sufficient to drive the system, since the infected host's individual fitness is now zero no matter what it does. The model requires only that the parasitoid, upon emerging from the host, be more likely to infect the host's kin than nonkin, and that the kin's reproductive success be increased due to the lowered risk of parasitism. Favorable situations for this behavior include groups of colonial or social hosts, or members of host populations with low dispersal rates and a relatively high degree of inbreeding. Parasitoid species particularly vulnerable to this sort of "thwarting" would be those with relatively small search ranges or areas of discovery.

The Lepidoptera will probably prove to be a fruitful group in which to search for "host suicide"-first because there is relatively more known about the natural history of butterflies than most other insects (or most other invertebrates, for that matter). More importantly, the demography of many species may fit the requirements for evolution of host suicide outlined above.

The females of many lepidopteran species lay their eggs in large clusters, creating an initial concentration of siblings, and the larvae themselves are slow to disperse. Moreover, many lepidopteran species are monophagous or oligophagus, and require specific food plants for their larvae. The monophagous habit can act to further isolate groups of relatively closely related larvae. Finally, those monophagous species which depend on scarce or very patchily distributed food plants, or species which depend on patchy or ephemeral habitats, are ideal groups in which to look for this behavior.

A specific example of a potential research subject is the Baltimore, Euphydryas phaeton (Nymphalidae). The Baltimore is "widespread but intensely local" (Klots 1951) since the larvae feed almost exclusively on Turtlehead, Chelone glabra (Scrophulariaceae), an uncommon and very patchily distributed plant. Klots (1951) asserts that adults of the Baltimore rarely wander more than several hundred meters from the Turtlehead plants.

An example of what appears to be host suicide behavior has been reported by Shapiro (1976). Larvae of the Nymphalid butterfly Chlosyne harrissii are parasitized by a species of braconid wasp. Unlike normal larvae, the parasitized larvae perch at the tops of tall herbs where they are extremely conspicuous. In the lab parasitized individuals do not feed or show escape reactions. It appears unlikely that these behavioral changes are the result simply of damage to the nervous system. It has been shown that a related braconid parasitoid refrains from eating the host's nervous system and kills the host only after the latter has found a safe pupation site.

Populations of Chlosyne harrissii show the characteristics expected if this behavior on the part of infected individuals were to have selective value. Chlosyne harrissii is a colonizing successional species. The scattered populations are probably founded by single, singly mated females. Each population persists only a few 
seasons and is highly inbred, so that most of the individuals in any locale are apt to be relatives whose fitnesses should be improved by a reduction in the parasite pressure on their progeny.

Parasitic castrator-host interactions. - Parasitic castration has been defined as "a destruction or alteration of gonad tissue, reproductive behavior, hormonal balance, or other modification of host reproductive effort above and beyond that which results from nonselective use of host energy reserves by the parasite" (Baudoin 1975).

Many parasitic castrators have a free-living stage and so do not necessarily depend upon the activities of the host for dispersal. Any behavioral and physiological modifications performed are expected to increase the amount of energy available to the parasite and reduce the risk of accidental death of the host. One advantage of castration is that the parasite can obtain energy from host tissues while not increasing host mortality (Obrebski 1975). Reproductive behaviors such as nest building, courtship, and male-male competition may be affected.

There are numerous studies of the effects of castrating parasites on crustacean physiology and morphology (Cattley 1948; Hartnoll 1962; Rasmussen 1959; reviews by Baudoin 1975; Kuris 1974; Reinhard 1956).

Strepsipterans (Insecta: Strepsiptera) are parasitic castrators which attack hymenopterans and other insects. Hymenopteran females. show reduced nest building behavior and do not forage as often for food for their larvae when infected with strepsipterans (Baer 1951). Female Andrena bees infected with strepsipterans have reduced scopae and seldom carry any pollen to the nest; infected digging wasps show unworn mandibles, while normal females have worn mandibles, indicating that infected females do not dig nests (Baudoin 1975).

Castration is usually permanent, resulting in total sterility. In some cases it may be temporary, resulting in sterility during the period of infection, or relative, resulting in reduced reproductive output (Baudoin 1975; Pike 1960).

The host infected with a castrator, like one infected with a parasitoid, can act in a manner conspicuous to predators, or "attempt suicide." However, since the host's reproductive effort may not in all cases be reduced to zero, it is more difficult to determine what circumstances will make aberrant behavior, or suicide, a viable alternative to life. In cases in which the host is permanently and totally sterilized, the same arguments that applied to hosts infected with parasitoids will apply. If sterilization is not permanent or total, suicide will be adaptive if the net gain in inclusive fitness resulting from suicide exceeds the loss of possible personal reproductive effort.

West Eberhard (1975) has proposed a series of expressions which describe the conditions necessary for an altruistic act on the part of an individual, $A$, towards a beneficiary, $B$, to have a positive selective value from the viewpoint of any given member of the population ("Ego"). When Ego and the altruist are one and the same individual, and several individuals in the population are beneficiaries of $A$ 's act, the expression

$$
\frac{1}{2} \Delta a_{A}+\sum_{i=1}^{n}\left(r_{B y} \Delta a_{B}\right)_{i}>0
$$


describes the conditions under which $A$ 's altruistic act will increase $A$ 's inclusive fitness. Here $a$ is fitness, $\Delta a_{A}$ is the change in $A$ 's fitness as a result of its altruistic act, $\Delta a_{B}$ is the change in the fitnesses of the beneficiaries as a result of $A$ 's altruistic act, $r_{B y}$ is the probability that $A$ and the young of $B$ share a given gene by common descent, and $n$ is the number of beneficiaries (West Eberhard 1975).

This expression is directly applicable to the situation faced by a host infected by a parasitic castrator. In this case suicide is beneficial if the cost of the suicide, in terms of the loss of all future reproductive output, is outweighed by the increase in inclusive fitness caused by reduced risk of parasitic infection for kin.

In cases in which a large number of relatives may be affected, in which the relatives share a large portion of their genome with the host, or in which the host's own reproductive fitness is greatly lowered, aberrant behavior on the part of infected hosts can be selected for.

Interactions between single-host true parasites and hosts. - True parasites with a single host (group 3) may or may not have a free-living stage. If a free-living stage is present the group 3 parasite, like parasitoids and castrators, need not depend upon the host for dispersal. If the group 3 parasite has no free-living stage, survival of the propagules depends upon their contact with a member of the host species. Modification of the host's behavior, whether to promote dispersal of parasite propagules or to alter the host's energy budget, is expected to be rare among group 3 parasites.

First, a single host usually harbors a large number of group 3 parasites. Any parasite with the ability to modify the host's behavior would share the benefits with all the other parasites present, while incurring all the expense itself. If all the parasites in the host were closely related or identical (or if the cost of producing the modification were small) this would present no problem. However, group 3 parasites sharing a host are typically unrelated (but see Wilson 1975, 1977, for a group selection model for the spread of such a trait).

Second, the cost of producing such a change in the host's behavior probably makes such a strategy nonadaptive for group 3 parasites. If the benefactor parasite (I use the term benefactor here only to mean the performer of an act that benefits some number of recipients) increases its fitness relative to that of parasites in other hosts, the beneficent trait can be selected for even if other unrelated parasites in the same host receive a greater increase in fitness than the benefactor parasite (Wilson 1975, 1977).

However, group 3 parasites are small, typically several orders of magnitude smaller than their hosts. Since the true parasite is so much smaller than the host, the amount of energy (in the form of mechanical stimulation or chemical production) a single parasite individual would need to expend to influence the behavior of a host would be prohibitively expensive. Instead of increasing its fitness relative to that of parasites in other hosts, the benefactor would show unchanged or reduced fitness relative to the fitnesses of parasites in both of its own and other hosts. If the benefactor is thus reducing its own fitness relative to all other parasites, and if the other parasites in its own host are unrelated, selection for beneficence will not occur.

Interactions between hosts and multiple-host true parasites. - The multihost 
true parasite (group 4) matures and reproduces in association with a definitive host. Immature stages pass through one, two, or three intermediate hosts. The intermediate hosts may be facultative or obligatory.

The addition of intermediate hosts adds a new level of complexity to the host parasite interactions. A single group 4 parasite may employ different strategies of energy budget modification and different strategies for dispersal of propagules in each of its hosts, and in some cases may employ the strategies of parasitoids and castrators. For example, Ocheotosoma aniarum (Trematoda: Plagiorchiidae) uses a different method to enter each of its three hosts. Eggs are released into the environment and hatch only after they are ingested by a snail. The xiphidiocercariae actively escape from the snail's body and penetrate the body of a tadpole. There they encyst, and enter the final host when the tadpoles are eaten by snakes (Cheng 1973).

Dispersal to the next in a series of hosts can be accomplished in a number of ways. If a free-living stage is present, such as the cercariae of some digenetic trematodes, this form can seek out and penetrate a new host. Cercariae of Schistosoma mansoni (Trematoda: Schistosomatidae) actively burrow through the skin of their mammalian definitive hosts.

If there is no free-living stage the group 4 parasite may depend upon passive contact with the next host, as shown above in the example of the eggs of Ochetosoma aniarum, or it may alter the behavior of one host to facilitate dispersal to the next.

Modification of the definitive host's behavior, for purposes of parasite dispersal or energy budget manipulation, is expected to be rare for the same reasons outlined above for the single-host parasite.

However, the portions of the group 4 parasite's life cycle which occur in the intermediate hosts may resemble the life cycles of parasitoids or castrators. That is, the intermediate host in a complex life cycle is sometimes occupied by a single parasite individual or a clone, and the parasite may be large relative to the intermediate host. In these cases, all the types of behavioral modification and energy budget modification which were profitable for the parasitoid and parasitic castrator will be profitable for the group 4 parasite in its intermediate host.

If an intermediate host is a normal prey item of the definitive host, dispersal to the latter can be accomplished by increasing the probability that the infected intermediate hosts will be eaten by the definitive host. One tactic is to cause the intermediate host to enter an environment where it is less efficient at avoiding predators or where predators are more efficient hunters.

Bethel and Holmes (1973) report on a series of studies carried out on the crustacean intermediate host, Gammarus lacustris (Crustacea: Gammaridae), infected with Polymorphus paradoxus (Acanthocephala). The infected gammarids lose their negative phototactic responses and become positively photatactic. When disturbed they do not dive to the bottom but cling tenaciously to floating vegetation. Feeding experiments with mallard ducks show that these infected gammarids make exceptionally easy prey for waterfowl, the definitive hosts (Holmes and Bethel 1972).

The intermediate stages of group 4 parasites may also act as castrators. For 
example, the sporocysts of Bucephalus cuculus (Trematoda: Bucephalidae) cause castration in the intermediate host, the oyster Crassostrea virginica (Cheng 1973). The tapeworm Paricterotaenia paradoxa causes castration in its intermediate host, the earthworm Allolobophora terrestris (Burt 1970).

The liver fluke of the genus Dicrocoelium presents a complex example of behavioral manipulation of an intermediate host to facilitate dispersal to a definitive host. Dicrocoelium (Trematoda: Dicrocoeliidae) is found in the bile ducts of sheep, cattle, deer, and other grazing mammals (Anokhin 1966; Cheng 1973; Wickler 1976). Eggs are released in the feces of the definitive hosts and are ingested by the first intermediate host, a land snail. In the snail the miracidia of the parasite reproduce asexually, forming mother and daughter sporocysts. The daughter sporocysts give rise to the cercariae larvae. These larvae are passed out of the snails in slime balls. Since reproduction in the snail host is asexual, all the larvae in a given slime ball are presumably genetically identical. These slime balls are eaten by ants of the genus Formica. In the ant, all the cercariae except one encyst in the abdomen; the remaining one encysts near the subesophageal ganglion (Wickler 1976).

These ants show temperature and humidity dependent abnormal behavior. In the evenings when temperature drops and humidity rises the ants leave the nest and affix themselves by the mandibles to the tips of grass blades. They then sink into a torpor and are not roused until the following morning. This places the ant in a highly vulnerable position during the optimal foraging time of the definitive hosts. Cattle and other grazing mammals are infected when they eat the infected ants (Anokhin 1966).

This system illustrates a number of interesting points. First, only those cercariae which encyst in the ant's abdomen survive to reproduce in the vertebrate host. The metacercaria encysted in the subesophageal ganglion does not reproduce (Wickler 1976). However, it is not genetically dead, as it is genetically identical with the other metacercariae in the ant. This resembles the situation found in many parasitoid-host systems. It was noted above that modification is most likely to occur when a single large parasite or clone occupies the host.

The type of abnormal behavior shown by the infected ants is interesting in itself. Wickler (1976) notes that this is a phylogenetically old sleeping behavior which is still shown by some nonsocial hymenoptera. This suggests that the abnormal behavior induced by the parasite may be a stereotyped behavioral pattern already programmed in the animal's nervous system, but normally never used or used in a different context. The parasite need not direct the host through a complex series of behaviors. Instead, mechanical stimulation by the parasite or the release of secondary compounds by the parasite may accidentally trigger the performance of a stereotyped behavioral pattern. If this induced behavior on the part of the host increases the parasite's chances of entering the next host, natural selection can act to reinforce the production of mechanical or chemical stimulation by the parasite.

\section{EVOLUTION OF MULTIPLE-HOST LIFE CYCLES}

There are striking similarities between the parasite-induced abnormal behavior shown by some intermediate hosts when infected by group 4 parasites and the 
suicidal behavior shown by some animals when infected by parasitoids. Larvae of Chlosyne harrissii infected with a parasitoid wasp perch on exposed vegetation (Shapiro 1976). Among intermediate hosts infected with immature stages of group 4 parasites, similar behaviors can be seen. Ants infected with Dicrocoelium affix themselves to blades of grass during the time of day when grazing mammals forage. (Anokhin 1966). The snail Succinea putris infected with the trematodes Leucochloridium macrostomum and $L$. paradoxum develop brightly colored, pulsating, sporocyst-packed antennae and show increased positive phototropism. As a result these conspicuous snails also perch on exposed vegetation (Wickler 1968; Wright 1966). All these behaviors place the host in situations where it is more vulnerable to predation and alter or eliminate the infected host's escape responses. These similarities suggest some possible routes for the evolution of multihost life cycles.

There are two possible categories of complex parasitic life cycles: those in which the present definitive host was once the only host in a single host cycle (DF, for definitive first) and those in which the present intermediate host was once the only host (IF, for intermediate first).

Evolution of DF life cycles.-Among parasite species which broadcast large numbers of propagules into the environment, a substantial number of propagules are eaten by nonhost species. If the nonhost species which preys upon the parasite propagules is itself a regular part of the host's diet, parasites with the ability to survive passage through an intermediate would have a selective advantage over those parasites which perished when eaten by the wrong species.

This broadcast method of reproduction and dispersal is most typical of group 3 parasites.

Evolution of IF life cycles. - At least two routes could lead to the evolution of IF multihost life cycles. In the first route infected hosts are occasionally eaten by predators. If some parasite individuals develop the ability to survive and reproduce within the predator they will have a selective advantage over those individuals which are unable to reproduce after their host is eaten by a predator. Since parasitoids and castrators tend to shorten the life span of the host more than group 3 parasites do, the host infected with a group 3 parasite will be exposed to predation for a longer period of time.

The second route to evolution of IF life cycles involves host suicide. Under special conditions an infected host may behave aberrantly and increase its risk of death by predation. However, a parasite which was able to survive and reproduce in the predator would have a selective advantage over those parasites which perished along with their hosts. The original parasite here is a parasitoid or castrator. (The hosts must also conform to fairly rigid specifications-local populations with low dispersal, high degree of relatedness, etc.)

Once two-host parasitic cycles have become established, it is the new two-host parasite and not the host which benefits from the host's suicidal behavior. It is expected that the parasite would "attempt" to maintain the suicidal behavior patterns on the part of the intermediate host, since they now facilitate the parasite's entry into the new definitive host.

Origins of modern multiple-host life cycles. - Since DF multihost parasites have retained the original host of the ancestral one-host cycle as the definitive host, 
closely related species of DF parasites are expected to have definitive hosts which are also closely related. The intermediate hosts are not expected to be closely related-they are simply the species whose ancestors happened to feed on parasite propagules.

Intermediate-first parasites have retained the host of the original one-host cycle as the intermediate host. Closely related species of IF parasites are expected to have intermediate hosts which are relatively closely related, while the definitive hosts may belong to a variety of taxa.

Two routes were discussed for the evolution of IF multihost life cycles. In the first route the original parasite was most likely to have been a single-host true parasite (group 3). Thus the intermediate stages of modern parasites which evolved by this route may be expected to resemble single-host true parasites. In the second route, the original parasite was a castrator or parasitoid. The intermediate stages of modern group 4 parasites which evolved by this route should resemble parasitoids or castrators in terms of size relative to the intermediate host, number of parasites per host, and effects on the intermediate host's reproductive success.

Thus, by examining the taxonomic relations of the host species of closely related groups of parasites, and by studying the biology of parasites in their intermediate hosts, it should be possible to determine which groups of modern group 4 parasites (if any) evolved by each of these three routes to a multihost life cycle.

\section{CONCLUSIONS}

It is necessary, of course, to put these ideas into perspective. Obviously, not all aspects of host-parasite behavioral interactions can be explained using these concepts alone. Parasitic life cycles involving one host (i.e., the parasitoid, castrator and single-host true parasite life cycles) have arisen in many taxa and from a variety of interspecies relationships. Some parasitic life cycles, such as those of gastropod molluscs which parasitize bivalves (Baer 1951), appear to have evolved from predator-prey interactions. Others appear to have evolved from commensal and ectoparasitic relations. The historical aspects of a particular parasite-host relationship may have an effect on the behavioral interactions observed between the two species.

Similarly, the simplified pattern relating phylogeny, behavior, and the route to evolution of a complex life cycle may be obscured by convergences. For example, consider a multihost true parasite which evolved from a single-host true parasite. If, for whatever reason, only a single parasite larva occupied each intermediate host, selection might favor those traits commonly associated with parasitoids and castrators-large body size and modification of host behavior.

Finally, various constraints may act upon a given species to make host-suicide and/or modification of host behavior unprofitable. For instance, a member of a cryptic or mimetic species, although infected with a parasitoid and living in small inbred populations, may find suicide disadvantageous because it would give predators valuable experience. 
Nonetheless, the concepts of host-suicide and behavioral manipulation do have value in deciphering the evolution of parasitic life cycles. First, these two concepts underscore the point that the host-parasite relationship, like any relationship between two species, is not static or unchanging. The behavior, ecology, and physiology of modern parasites and their hosts do not in any sense represent the culmination of the evolutionary process; instead they reflect the current status of an ongoing series of manipulations and retaliations.

In addition, the concepts of host-suicide and behavioral manipulation shed some light on the question of why complex parasitic life cycles exist at all. Hyman (1951), in her discussion of the digenetic trematodes, phrases the question this way: "Perhaps the most remarkable feature of the parasitic flatworms is the complexity of the life cycle. This cycle involves one to three intermediate hosts in flukes and cestodes and as many larval stages. It is difficult to understand what advantage accrues to the parasite from such complexity; in fact the chances of offspring reaching the definitive host and maturing to the reproductive stage would seem to be greatly reduced by this round-about way of reaching adulthood."

It is often postulated that the complex parasitic life cycle reduces competition between adult parasites and immature stages. However it is also possible to view the complex life cycle, not (or not only) as a complex strategy to prevent parentoffspring competition, but as the parasite's way of making the best of a bad situation; in other words, as an evolutionary reaction to a host species' suicidal behavior. The next step for the parasite, in an evolutionary sense, would be to eliminate some of the intermediate hosts. This is indeed a trend seen in many parasitic groups.

\section{SUMMARY}

Parasites and their hosts show behavioral as well as physiological interactions. Parasites are able to alter the behavior of their hosts, and hosts in turn may employ behavioral retaliation in response to parasitic infection.

The four types of endoparasites discussed in the paper are parasitoids (group 1), parasitic castrators (group 2), single-host true parasites (group 3) and multihost true parasites (group 4). For each of these four types of parasites the role of parasite induced modifications of host behavior is analyzed with respect to (1) dispersal of the parasite propagules to new hosts, (2) modification of the host's energy budget to provide energy for the parasite's growth and maturation, and (3) keeping the host alive until the parasite has completed its life cycle.

It is found that modification of the host's energy budget is profitable for parasitoids and castrators, but not for group 3 parasites. During some stages of its life cycle the group 4 parasite can employ modification of the host's energy budget, but only if the larval parasite resembles parasitoids or castrators in certain ways.

Modification of host behavior to facilitate dispersal of propagules to new hosts, or to the next host in a series of hosts, should be employed most often by the intermediate larval stages of group 4 parasites.

The reproductive fitness of the host is reduced by its parasitic load. A parasitoid 
or castrator may reduce the host's reproductive fitness to zero, while a single- or multiple-host true parasitic infection may scarcely impair it. A host may defend itself by preventing infection, or, once infected it can protect its kin by attempting to prevent their infection. Host suicide is the term coined to describe aberrant behavior on the part of an infected host which leads to increased probability of death by predation. Host suicide will increase the inclusive fitness of the host if (1) the suicide prevents the maturation of the parasite; (2) the mature parasite is more likely to infect the host's kin than nonkin; and (3) the benefit to the host, in terms of the increased fitness of the kin, is greater than the cost of the suicide, measured in terms of the loss of the host's own reproductive fitness.

Host suicide is most profitable when the host is infected by a parasitoid. The parasitoid reduces the host's reproductive fitness to zero, so that the cost of the suicide is also zero. Suicide is of variable value when the host is infected by a castrator, the value depending on the degree to which the parasitoid reduces the host's reproductive fitness. Host suicide is not expected when the host is infected with group 3 or 4 parasites. Mature parasitoids may be more likely to infect the host's kin than nonkin in social or colonial animals, or in species with small, isolated, inbred populations.

The similarity between host suicide and the passage of group 4 parasites from intermediate hosts to definitive hosts is noted, and the possible role of host suicide in the evolution of such complex parasitic life cycles is examined.

\section{ACKNOWLEDGMENTS}

I thank R. Buskirk, G. Hausfater, M. Litte, A. Shapiro, J. Stamps, and P. Trail for advice and critical reading of the manuscript. This work was supported by a National Science Foundation predoctoral fellowship.

LITERATURE CITED

Anokhin, A. I. 1966. Daily rhythm in ants infected with metacercariae of Dicrocoelium lanceatum. Dokl. Akad. Nauk S.S.S.R. 166:757-759.

Askew, R. R. 1971. Parasitic insects. Heinemann Educational, London.

Baer, J. G. 1951. Ecology of animal parasites. University of Illinois Press, Urbana.

Baudoin, M. 1975. Host castration as a parasitic strategy. Evolution 29:335-352.

Bethel, W. M., and J. C. Holmes. 1973. Altered evasive behavior and responses to light in amphipods harboring acanthocephalan cystacanths. J. Parasitol. 59:945-956.

Burt, D. R. R. 1970. Platyhelminthes and parasitism-an introduction to parasitology. American Elsevier, New York.

Cattley, J. G. 1948. Sex reversal in copepods. Nature (Lond.) 161:937.

Cheng, T. C. 1968. The compatibility and incompatibility concept as related to trematodes and molluscs. Pac. Sci. 22:141-160. 1973. General parasitology. Academic Press, New York.

Dence, W. A. 1958. Studies on Ligula-infected common shiners (Notropis cornutus frontalis Agassiz) in the Adirondacks. J. Parasitol. 44:334-338.

Eibl-Eibesfeldt, I., and F. Eibl-Eibesfeldt. 1967. Das Parasitenabwehren der Minima-Arbeiterinnen der Blattschneider Ameise (Atta cephalotes). Z. Tierpsychol. 24:278-281.

Fisher, F. M., and R. C. Sanbourn. 1964. Nosema as a source of juvenile hormone in parasitized insects. Biol. Bull. 126:235-252. 
Hamilton, W. D. 1964. The genetical theory of social behavior, I and II. J. Theor. Biol. 7:12-45. 1972. Altruism and related phenomena, mainly in social insects. Annu. Rev. Ecol. Syst. 3:193-232.

Hartnoll, R. G. 1962. Parasitic castration of Microsporidia longirostris (Fabricius) by a sacculinid. Crustaceana 4:295-300.

Holmes, J. C., and W. M. Bethel. 1972. Modification of intermediate host behavior by parasites. Pages 123-149 in E. U. Canning and C. A. Wright, eds. Behavioral aspects of parasite transmission. Zool. J. Linn. Soc. 51 Suppl. 1.

Hulscher, J. B. 1973. Burying depth and trematode infection in Macoma balthica. Neth. J. Sea Res. 6:141-156.

Hyman, L. H. 1951. The invertebrates: platyhelminthes and rhynchocoela, the acoelomate bilateria. McGraw-Hill, New York.

Klots, A. B. 1951. The Peterson field guide series: a field guide to the butterflies of North America east of the Great Plains. Houghton Mifflin, Boston.

Kuris, A. M. 1974. Trophic interactions and similarity of parasitic castrators to parasitoids. Q. Rev. Biol. 49:129-148.

Lester, R. J. G. 1971. The influence of Schistocephalus pleurocercoids on the respiration of Gasterosteus and a possible resulting effect on the behavior of the fish. Can. J. Zool. 49:361-366.

Negus, M. R. S. 1968. The nutrition of sporocysts of the trematode Cercaria doricha Rothschild, 1935 in the molluscan host Turritella communis Risso. Parasitology 58:355-366.

Obrebski, S. 1975. Parasite reproductive strategies and evolution of castration of hosts by parasites. Science 188:1314-1316.

Orr, T. S. C. 1966. Spawning behavior of Rudd Scardinius erythrophthalmius infested with plerocercoids of Ligula intestinalis. Nature (Lond.) 212:736.

Pan, C.-T. 1965. Studies on the host-parasite relationship between Schistosoma mansoni and the snail Australorbis glabratus. Am. J. Trop. Med. Hyg. 14:931-976.

Pike, R. B. 1960. The biology and post larval development of the bopyrid parasites Pseudione affinis G. O. Sars and Hamiarthus abdominalis (Kroyer) (=Phryxus abdominalis (Kroyer)). J. Linn. Soc. Lond., Zool. 44:239-251.

Rasmussen, E. 1959. Behavior of sacculinized shore crabs (Carcinus maenas Pennant). Nature (Lond.) 183:479-480.

Reinhard, E. G. 1956. Parasitic castration of crustacea. Exp. Parasitol. 5:79-107.

Salt, G. 1963. The defense reactions of insects to metazoan parasites. Parasitology 53:527-642.

Shapiro, A. 1976. Beau geste? Am. Nat. 110:900-902.

Slansky, F. 1978. Utilization of energy and nitrogen by larvae of the imported cabbage worm Pieris rapae, as affected by parasitism by Apanteles glomeratus. Environ. Entomol. 7:179-185.

Swennen, C. 1969. Crawling tracks of trematode infested Macoma balthica (L.). Neth. J. Sea Res. 4:376-379.

Swennen, C., and H. Ching. 1974. Observations on the trematode Parvatrema affinis, causative agent of crawling tracks of Macoma balthica. Neth. J. Sea Res. 8:108-115.

Uzmann, J. R. 1953. Cercaria milfordensis nov. sp. a microcercous trematode larva from the marine bivalve, Mytilus edulus L. with special reference to its effect on the host. J. Parasitol. 39:445-451.

West Eberhard, M. J. 1975. The evolution of social behavior by kin selection. Q. Rev. Biol. 50:1-33.

Whittaker, R. H., and P. P. Feeny. 1971. Allelochemics: chemical interaction between species. Science 171:757-770.

Wickler, W. 1968. Mimicry in plants and animals. McGraw-Hill, New York.

- 1976. Evolution-oriented ethology, kin selection, and altruistic parasites. Z. Tierpsychol. 42:206-214.

Wilson, D. S. 1975. A theory of group selection. Proc. Natl. Acad. Sci. USA 72:143-146.

1977. Structural demes and the evolution of group-advantageous traits. Am. Nat. 111:157-185.

Wright, C. A. 1966. The pathogenesis of helminths in the mollusca. Helminthol. Abstr. 35:207-225. 